\title{
Antioxidant Activity of Isoflavones from Tofu Pulp Waste
}

\author{
Sri Wahyuni ${ }^{*}$, Ratna ${ }^{2}$, Holilah $^{1}$, Asranudin $^{1}$, Raden Alip Raharjo $^{2}$
}

\begin{abstract}
Tofu pulp is a waste of manufacturing process of tofu. The aims of this study were to extraction the isoflavone compound from tofu pulp and determine the antioxidant activity of isoflavone. Extraction isoflavone of tofu pulp was conducted by maceration method using ehanol and ethyl acetate. Phytochemical test was conducted to ensure that the main content of tofu pulp is flavonoid compound. Antioxidant activity assay was carried out by DPPH $(2,2-$ diphenyl-1-picrylhydrazil) method. $\mathrm{IC}_{50}$ value was calculated to measure the difference of antioxidant activity in ethanol and ethyl acetate extracts. Isoflavone recovery of ethanol and ethyl acetate extracts were $29.1 \%$ and $13.93 \%$. Radical scavenging activity (RSA) of isoflavone extracted ethanol and ethyl acetate were $82.06 \%$ and $83.86 \%$. $\mathrm{IC}_{50}$ value of isoflavone from ethanol and ethyl acetate extracts were 8.05 and $14.59 \mathrm{ppm}$. Therefore, isoflavone extracted using ethyl acetate from tofu pulp has antioxidant activity better than ethanol extract.
\end{abstract}

Keywords - Isoflavone, tofu, pulp, antioxidant activity.

\section{INTRODUCTION}

Soybean is an important protein source for Indonesian people. About 90 percent of soybeans provided in Indonesia, used as food, feed and seed [1]. Generally, soy is more widely used as raw materials for food products, especially soybeans yellow. Processed soy products are very popular in Indonesia is tofu. The processing of soybeans into tofu produce liquid waste and solid waste. Liquid waste is usually disposed while the solid waste can be used for animal feed. Tofu pulp is waste generated from the processing of soybeans into tofu.

The content of secondary metabolites in soybeans such as isoflavones is metabolite product that very important for humans. Isoflavones are subclass from large group of flavonoids that have estrogenic activity or phytoestrogens [2]. There are four forms of the isoflavones found ie. glucosides (daidzin, genistin and glycitin); acetylglucosides (acetyldaidzin, acetylgenistin and acetylglycitin); malonylglucosides (malonyldadzin, malonylgenistin and malonylglycitin) and structure unconjugated aglycone (daidzein, genistein and glycitein) [3-4]. Isoflavones in soy is found in the form of genistein, daidzein and glycitein at various concentrations namely $1.45-4.59 \mathrm{mg} / \mathrm{g}$ [5]. Murphy et al. [6] reported that the aglycone, genistein and daidzein are the main ingredients in traditional fermented soybean products (miso and tempeh).

\footnotetext{
${ }^{1}$ Department of Food Science and Technology at the Faculty of Technology and Agricultural Industry, Halu Oleo University. Kendari, Southeast Sulawesi, Indonesia. ${ }^{2}$ Department of Chemistry Education at the Faculty of Teacher Training and Education, Universitas Halu Oleo. Indonesia
}

While non-fermented products (tofu), the form of isoflavones found are glucoside, genistin and daidzin. The research about activity of bioactive metabolites in soybeans has been widely reported. Epidemiological studies have shown a direct relationship between the protection of breast cancer and soy intake [7]. In prostate cancer, the chemopreventive effect of the soybean mediated by mechanisms of modulations of gene expression was evidenced in a study in which isoflavones derived from soybean cake exhibited antiproliferative effects on prostate cancer cells, decreasing the expression of cyclin B1 [8]. The habit of soy intake may be useful strategy for chemopreventive benefit of bioactive compounds in soybeans.

This research will be reported antioxidant activity extracted from solid and liquid waste processing soybeans into tofu. The waste is important to investigate in order to be used optimally. The allegation that isoflavone is contained in both waste, so do the extraction with ethyl acetate and ethanol. The antioxidant activity of the extracted was tested using DPPH.

\section{MATERIALS AND METHODS}

All materials that used in this work were analytical grade Ethanol (95\%) and ethyl acetate ( $\geq 99 \%)$ were purchased from Sigma-Aldrich, Singapore. HCl (35-38\%) and 2,2-Diphenyl-1picrylhydrazyl (DPPH) were purchased from Merck, Germany. Tofu pulp waste was taken from factory of tofu manufacturing in Kendari, Southeast Sulawesi, Indonesia.

\section{A. Preparation of waste pulp powder}

Tofu pulp obtained from factory of manufacturing tofu was heated at $60^{\circ} \mathrm{C}$ for $42 \mathrm{~h}$ to obtain dried tofu pulp. and then dried tofu pulp milled into powder, so powder tofu pulp was obtained.

\section{B. Moisture content of tofu pulp}

Moisture content of tofu pulp was analyzed using the standard method of AOAC [9].

\section{Extraction of Isoflavon}

Extraction of isoflavone was refered to the method that had been done by Carrāo-Panizzi et al. [10]. 40 grams of tofu pulp powder were macerated using solvent mixture of ethanol: $\mathrm{HCl}$ (8:1). Maceration was carried out for $36 \mathrm{~h}$ on shaker and filtered using Whatman paper No. 11. The filtrate was concentrated using rotary vacuum evaporator. Recovery was calculated by dividing the weight of the final dry extract by the sample weight and multiplied by $100 \%$. 


\section{Phytochemistry test}

Phytochemistry test was refered to the method that had been done by Bargah [11]. Each extract of ethanol and ethyl acetate was conducted several tests ie. saponin, alkaloid, flavonoid, terpenoid, steroid, tannin and phenol.

\section{E. DPPH radical scavenging capacity}

DPPH was dissolved in methanol to a concentration of $10-4 \mathrm{~mol} / \mathrm{L}$. DPPH radical scavenging capacity was estimated according to Blois [12] and Shyu and Hwang [13] with slight modification. Two milliliters of diluted extract was mixed with $2 \mathrm{ml}$ of DPPH solution, the mixture was kept in the dark for 60 min and the absorbance at $517 \mathrm{~nm}$ was measured. The scavenging capacity was calculated as $\left(1-\mathrm{Ab} / \mathrm{A}_{0}\right) \times 100 \%$ (where $\mathrm{Ab}$ is the absorbance at $517 \mathrm{~nm} ; \mathrm{A}_{0}$ refers to the absorbance of DPPH without sample added at $517 \mathrm{~nm}$ ).

\section{RESULT AND DISCUSSION}

\section{A. Extraction of isoflavone}

Soybean is the type of food that rich primary and secondary metabolites. Protein is an important content of primary metabolites in soybeans. Protein is the major constituent of the soybean (30 to $50 \mathrm{~g} / 100 \mathrm{~g}$ ), followed by carbohydrates (20 to $35 \mathrm{~g} / 100 \mathrm{~g}$ ) and lipids (15 to $25 \mathrm{~g} / 100 \mathrm{~g}$ ) [14-15]. While secondary metabolites lot of attention on soy is isoflavone (Naim et al., 1974). In this study, isoflavone extracted from solid waste of tofu pulp, which expected to remain high content of compounds. Recovery of isoflavone extract of tofu pulp using EtOAc and EtOH solvent is shown in Table 1.

\begin{tabular}{cc} 
TABEL 1. RECOVERY OF ISOFLAVONE OF TOFU PULP. \\
\hline Solvent & Recovery (\%) \\
\hline Ethyl acetate & $29.1 \%$ \\
Ethanol & $13.93 \%$ \\
\hline
\end{tabular}

Isoflavone extraction of tofu pulp effectively use the solvent ethyl acetate (29.1\%). Semipolar nature of ethyl acetate, make it easier to attract isoflavone component from parts of soy tissue. The form of isoflavones extracted from tofu pulp is glycosides such as genistin, daidzin and glisitin [16]. While the form of the isoflavones contained in soy derivative products involving fermentation process (miso and tempeh) is dominated by the aglycone form, namely daidzein, genistein and glycitein [5]. Recovery isoflavone which varies depending on the extraction method is performed. Zuo et al. [17] have been extracted the isoflavones with recovery reached $87.3 \%$ using supercritical carbon dioxide $\left(\mathrm{SC}-\mathrm{CO}_{2}\right)$.

Various techniques have been developed to extract the phenolic compounds, especially isoflavone. Several thousands different phenolics with wide range of polarities, forms (aglycon,glycosylated, acetylated/malonylated, esterified to acids, etc.) have been reported in literature. In addition, phenolic compounds may be associated with different cellular components such as cell walls, proteins, lipids etc [18]. Techniques for extraction of isoflavones from soybeans has been developed by many researchers as Murphy et al. [6]; Lee et al. [19]; Lin and Giusti [20] and Luthria et al. [18].

\section{B. Phytochemistry test}

Phytochemical screening is the first step to provide assurance that the extracted compounds are flavonoid that isoflavones. Phytochemical screening method is testing the reaction color with a color reagent. The results of phytochemical test isoflavone extract of ethanol and ethyl acetate are shown in Table 2.

TABEL II. PHYTOCHEMISTRY TEST OF TOFU PULP.

\begin{tabular}{ccc}
\hline \multirow{2}{*}{ Phytochemistry test } & \multicolumn{2}{c}{ Extract } \\
\cline { 2 - 3 } & Ethyl acetate & Ethanol \\
\hline Alkaloid & - & - \\
Flavonoid & + & + \\
Steroid & - & - \\
Terpenoid & - & - \\
Saponin & - & - \\
Phenol & - & - \\
Tannin & - & - \\
\hline
\end{tabular}

The results of the analysis of alkaloids in ethanol and ethyl acetate extracts showed negative results. Alkaloid test in ethanol and ethyl acetate extracts use Meyer, Dragendorf and Wagner reagents. The tests with three reagent does not produce any sediment so that the result is negative. Extracts were tested cause a reaction in red for ethyl acetate extract while the ethanol extract is purple yellow. The red solution indicates the sample contains flavonoids. The analysis of ethanol and ethyl acetate extracts showed negative steroidal/terpenoids. Test of ethanol and ethyl acetate extracts showed negative results to the saponin. extracts were analyzed did not produce froth/foam. The test of extract using reagents $\mathrm{FeCl}_{3}$ showed green-black color. This case shows that the extract does not contain tannin.

\section{Antioxidant activity}

Antioxidants are compounds that able to delay or inhibit oxidation processes caused by a wide range of reactive oxygen species (ROS) such as superoxide anion radicals, hydroxyl radicals and hydrogen peroxide, which produced by the enzymatic system. Antioxidants involved in the defense mechanism of the organism on the free radical attack. Antioxidants are divided into endogenous antioxidants (superoxide dismutase, catalase, glutathione peroxidase) and exogenous antioxidants (vitamin $\mathrm{E}$, vitamin $\mathrm{C}, \beta$-carotene, flavonoids (isoflavones), vitamin D and vitamin K) [21-22] based on source.

The antioxidant activity of ethanol and ethyl acetate extracts in tofu pulp have been used DPPH method. DPPH method is easy and simple method for estimating the ability of antioxidants capturing free radicals based on a decrease in absorbance at $517 \mathrm{~nm}$, due to inactivation of the radical $\mathrm{DPPH} \bullet$ by isoflavones. In DPPH test, the color purple chromogen radical (DPPH.) is reduced by antioxidants (AH) into a pale yellow hydrazine (DPPH-H) [12,23]. The antioxidant activity of ethanol and ethyl acetate extract of tofu pulp measured at concentrations of 5, 10, 25, 50, 75 and 100 ppm (Fig. 1). 


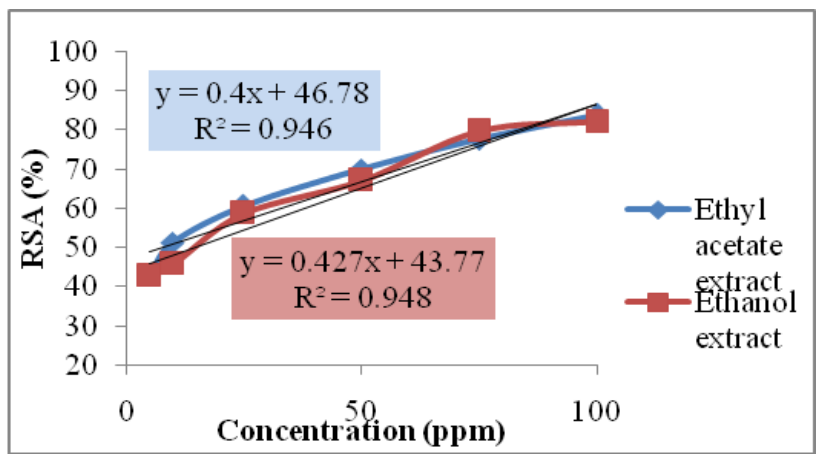

Fig. 1. Radical scavenging activity of isoflavone extract.

D. Determination of $I C_{50}$

Bioactive substances in plants has active absolute concentration pharmacologically when the concentration of $\mathrm{IC}_{50}<1000 \mathrm{ppm}$ and has active relative concentration of pharmacologically when the concentration $\mathrm{IC}_{50}>1000 \mathrm{ppm}$ [24]. The purpose of determination of $\mathrm{IC}_{50}$ was to show the effectiveness of the compound or quantitative measure of how many substances that would be required to inhibit the specific biological processes. IC50 value was based on the absorbance of the sample. $\mathrm{IC}_{50}$ value of ethyl acetate and ethanol extracts of tofu pulp were shown in Fig. 2.

$\mathrm{IC}_{50}$ (inhibition Concentration 50) is the concentration of antioxidant $(\mathrm{mg} / \mathrm{mL})$ which capable of providing radical percent reduction by $50 \%$ compared to control through an equation of line. $\mathrm{IC}_{50}$ value is obtained from the intersection of the lines between the $50 \%$ barrier with the axis of concentration. Blois [12] reported that a substance can be considered as powerful antioxidant if it has value of $\mathrm{IC}_{50}<200$ $\mathrm{mg} / \mathrm{mL}$.

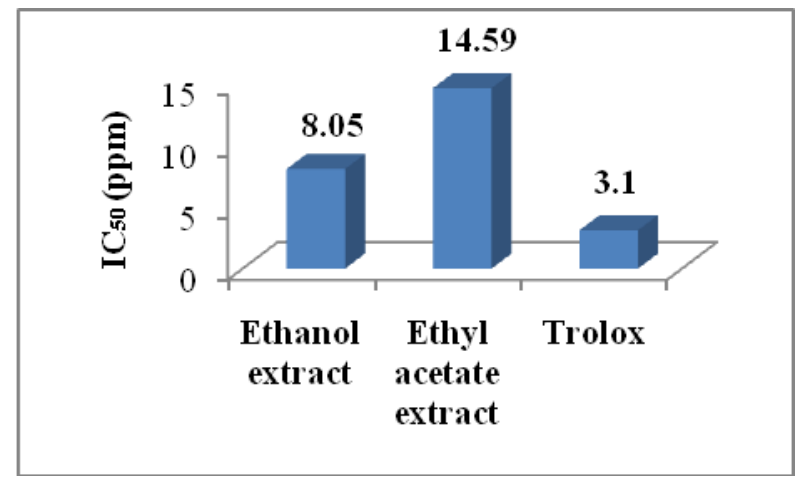

Fig. 2. $\mathrm{IC}_{50}$ value of isoflavone extract.

$\mathrm{IC}_{50}$ value of ethyl acetate and ethanol extracts obtained from the relationship with the concentration percentage of antioxidant activity (\%RSA) that produces linear regression equation ie. $\mathrm{y}=0.4 \mathrm{x}+46.78$ and $\mathrm{y}=0.427 \mathrm{x}+43.7$, respectively. $\mathrm{x}$ is $\mathrm{IC}_{50}$ value and $\mathrm{y}$ is 50 . So the value of $\mathrm{IC}_{50}$ of ethyl acetate and ethanol extracts approxymately 8.05 and 14.59 ppm. $\mathrm{IC}_{50}$ of both extracts are lower than the standard trolox (acid, 6-hydroxy-2,5,7,8-tetramethyl chromane-2carboxylic acid) is $3.11 \mathrm{ppm}$. Trolox is water soluble vitamin $\mathrm{E}$ analogue. In addition, there are other standard types commonly used ie. catechin, gallic acid, caffeic acid, pyrocatechol, oleuropein, ascorbic acid, chlorogenic acid, $\alpha$ tocopherol, resorcinol, butyl hydroxy toluene and p-coumarate acid.

The antioxidant activity of ethyl acetate extract of tofu pulp smaller than ethanol extract, shown on the differenceof $\mathrm{IC}_{50}$ value approxymately $6.54 \mathrm{ppm}$. It showed that ethyl acetate is solvent that can attract flavanoid compounds from soy tissues. The lower of $\mathrm{IC}_{50}$ value of the sample, the greater of the properties and the antioxidant activity.

\section{CONCLUSION}

Extraction of isoflavone compounds from tofu pulp have been successfully conducted. Isoflavone extract from ethyl acetate has higher antioxidant activity than ethanol extract. $\mathrm{IC}_{50}$ value for ethyl acetate extract is smaller than ethanol extract approxymately $8.05 \mathrm{ppm}$ and $14.59 \mathrm{ppm}$, respectively.

\section{ACKNOWLEDGMENT}

The authors acknowledge to the Directorate General of Strengthening Research and Development, Ministry of Research, Technology and Higher Education, Indonesia for financial support.

\section{REFERENCES}

[1] [FAOSTAT] Food and Agriculture Organization of Statistic. Statistical data of food balance sheet, www.fao.org. [Download December 2014], 2005.

[2] C. R. Cederroth, and S. Nef, "Soy, phytoestrogens and metabolism: A review," Molecular and Cellular Endocrinology, vol. 304, no. 1-2, pp. 30-42, 2009. https://doi.org/10.1016/j.mce.2009.02.027

[3] T. H. Kao, W. M. Wu, C. F. Hung, W. B. Wu, and B. H. Chen, "Antiinflammatory Effects of Isoflavone Powder Produced from Soybean Cake," Journal of Agricultural and Food Chemistry, vol. 55, no. 26, pp. 11068-11079, 2007. https://doi.org/10.1021/jf071851u

[4] C. A. S. P. Pereira, and F. B. Oliveira, Soja, alimento e saúde: valor nutricional e preparo UFV," Viçosa: 2002.

[5] H. S. D. Martino, C. L. de Morais, S. M. R. Ribeiro, D. M. I de Souza, N. D. Piovesan, and E. De Mejía, Nutritional and Bioactive Compounds of Soybean: Benefits on Human Health, Brazil: InTech, 2011, pp. 465470.

[6] P. A. Murphy, K., Barua, and C. C. Hauck, "Solvent extraction selection in the determination of isoflavones in soy foods," Journal of Chromatography B, vol. 777, pp. 129-138, 2002. https://doi.org/10.1016/S1570-0232(02)00342-2

[7] J. Y. Dong, and L. Q. Qin, 'Soy isoflavones consumption and risk of breast cancer incidence or recurrence: a meta-analysis of prospective studies," Breast Cancer Research and Treatment, vol. 125, no. 2, pp. 315-323, 2011. https://doi.org/10.1007/s10549-010-1270-8

[8] M. Messina, "Soy, soy phytoestrogens (isoflavones), and breast cancer," American Journal of Clinical Nutrition, vol. 70, pp. 574-575, 1999.

[9] [AOAC)] Association of Official Agricultural Chemists, Official methods of analysis, 15th ed. (Association of Official Analytical Chemists, Washington, DC: 1990).

[10] M. C. Carrão-Panizzi, F. S. P. de Goés, and A. Kikuchi, "Extraction Time for Soybean Isoflavone Determination", Brazilian archieves of Biology and Technology, vol. 45, no. 4, pp. 515-518, 2002.

[11] R. K. Bargah, "Preliminary test of phytochemical screening of crude ethanolic and aqueous extract of Moringa pterygosperma Gaertn," Journal of Pharmacognosy and Phytochemistry, vol. 4, no. 1, pp. 0709, 2015. 
[12] M. S. Blois, "Antioxidant determination by the use of a stable free radical," Nature, vol. 181, pp. 1199-1200, 1958. https://doi.org/10.1038/1811199a0

[13] Y. S. Shyu, and L. S. Hwang, "Antioxidant activity of the crude extract of lignan glycosides from unroasted Burma black sesame meal," Food Research International, vol. 35, pp. 357-365, 2002. https://doi.org/10.1016/S0963-9969(01)00130-2

[14] A. W. Carvalho, C. O. Silva, M. I. S. Dantas, D. I. G. Natal, S. M. R. Ribeiro, N. M. B. Costa, and H. S. D Martino, "The use hull soybean flour of heat-treated grains does not affect iron bioavailability in rats," Archivos Latinoamericanos de Nutrición, vol.in press, 2011.

[15] E. A. Esteves, H. S. D. Martino, F. C. E. Oliveira, J. Bressan, and N. M. B. Costa, "Chemical composition of a soybean cultivar lacking lipoxygenases (LOX2 and LOX3)," Food Chemistry, vol. 122, no. 1, pp. 238-242, 2010 https://doi.org/10.1016/j.foodchem.2010.02.069

[16] M. B. Naim, S. Gestetner, Y. Zilkah, Bilk, and A. Bondi, "Soybean isoflavone, characteristic, determination and antifungal activity," Journal of Agriculture and Food Chemistry, vol. 22, no. 5, pp. 806809, 1974. https://doi.org/10.1021/jf60195a031

[17] Y. B. Zuo, A.W. Zeng,, X.G. Yuan, and K.T. Yu, "Extraction of soybean isoflavone from soybean meal with aqueous methanol modified supercritical dioxide," Journal of Food Engineering, vol. 89, no. 4, pp. 384-389, 2008.

[18] D. L. Luthria, R. Biswasa, and S, Natarajan, "Comparison of extraction solvents and techniques used for the assay of isoflavones from soybean," Food Chemistry, vol. 105, pp. 325-333, 2007. https://doi.org/10.1016/j.foodchem.2006.11.047

[19] J. H. Lee, M. Renita, R. J. Fioritto, S. K. Martin, S. J. Schwartz, and Y. Vodovotz, "Isoflavone characterization and antioxidant activity of Ohio soybeans," Journal of Agricultural and Food Chemistry, vol. 52, pp. 2647-2651, 2004. https://doi.org/10.1021/jf035426m

[20] F. Lin, and M. M. Giusti, "Effects of solvent polarity and acidity on the extraction efficiency of isoflavones from soybeans (Glycine max)," Journal of Agricultural and Food Chemistry, vol. 53, pp. 3795-3800, 2005. https://doi.org/10.1021/jf050030r

[21] A. M. Pisoschi, and G. P. Negulescu, "Methods for Total Antioxidant Activity Determination: A Review," Biochemistry \& Analitical Biochemistry, vol. 1, no. 1, 2011.

[22] C. Dionysios, C. Fotakis, C. Nikokavoura, A. Papadopoulos, K. Antony, and C. Calokerinos, "Modified DPPH and ABTS Assays to Assess the Antioxidant Profile of Untreated Oils," Food Analytical Methods, vol. 8, no. 5, pp. 1294-1302, 2015 https://doi.org/10.1007/s12161-014-0005-6

[23] M. Elmastas, I. Gu“lc,in, S. Beydemir, O.Ï. Ku“freviog lu, and H. Y. Aboul-Enein, "A study on the in vitro antioxidant activity of juniper (Juniperus communis L.) seeds extracts," Analytical Letters, vol. 39, pp. $47-65,2006$ https://doi.org/10.1080/00032710500423385

[24] Neubig, "International Union of Pharmacology Committe on Receptor Nomenclature and Drug Classification," Pharmacol Wahyu, vol. 55, no. 4, pp. 597-606, 2003. 